management, sputum collection, and discussions. MD performed the laboratory examinations in Baku, prepared the sputum specimens, and participated in discussion and analysis of the data. FJ was in charge of patient management, IJ participated in the patient management. AI helped with laboratory examinations and sputum collection. FM helped with patient management and data collection. $\mathrm{RdeH}$ initiated the project and participated in the discussion and analysis of the data and in writing the paper. FP participated in the analysis of specimens, discussion and analysis of the data, and writing the paper.

Funding: The Damien Foundation (Brussels) partly funded the laboratory investigations in Antwerp and the Zurich Lung Association those in Zurich.

Conflict of interest: None.

1 World Health Organisation. Tuberculosis trends in central and eastern Europe and countries of the former USSR. Wkly Epidemiol Rec 1995;4:21-4.

2 Raviglione MC, Rieder HL, Styblo K, Khomenko AG, Esteves K, Kochi A. Tuberculosis trends in eastern Europe and the former USSR. Tubercle Lung Dis 1994;75:400-6.

3 Coninx R, Eshaya-Chauvin B, Reyes H. Tuberculosis in prisons. Lancet $1995 ; 346: 1238-9$.

4 European Centre for the Epidemiological Monitoring of AIDS HIV/AIDS surveillance in Europe. Quarterly report (No 52). Saint Maurice, France: ECEMAIDS, 1996:11.
5 Khomenko AG. The course and outcome of pulmonary tuberculosis due to drug resistant mycobacteria. 17th Annual meeting, European Society for Mycobacteriology. Paris: Institut Pasteur, 1996.

6 Drobniewski F, Taylor E, Ignatenko N, Paul J, Conolly M, Nye P, et al. Tuberculosis in Siberia. 1. An epidemiological and microbiological assessment. Tubercle Lung Dis 1996;77:199-206.

7 World Health Organisation. WHO report on the tuberculosis epidemic, 1995. Stop TB at the source. Geneva: WHO, 1995. (WHO/TB/95.183.)

8 International Union Against Tuberculosis and Lung Disease. Tuberculosis guide for low income countries. 4th ed. Paris : IUATLD, 1996.

9 World Health Organisation. Treatment of tuberculosis. Guidelines for national programmes. Geneva: WHO, 1993. (WHO/TB.91.161.)

10 Kent PT, Kubica G. Public health mycobacteriology. A guide for the level IIt laboratory. Atlanta: US Department of Health and Human Services, Centers for Disease Control, 1985

11 Morgan MA, Horstmeier CD, De Young DR, Roberts GD. Comparison of a radiometric method (BACTEC) and conventional culture media for recovery of mycobacteria from smear-negative specimens. J Clin Microbiol 1983;18:384-8.

12 Inderlied CB, Nash K. Antimycobacterial agents: in vitro susceptibility testing, spectra of activity, mechanisms of action and resistance, and assays for activity in biologic fluids. In: Lorian V, ed. Antibiotics in laboratory medicine. 4th ed. Baltimore: Williams and Wilkins, 1996:127-75.

13 Kluge H. TB programme in Siberia. Like a scene from an old movie. Contact 1997;45:24.

(Accepted 5 February 1998)

\title{
Prospective, hospital based study of fever in children in the United Kingdom who had recently spent time in the tropics
}

\author{
John L Klein, Guy C Millman
}

Published data are lacking on the subject of imported infections in children. As general practitioners and paediatricians in the United Kingdom are frequently involved in the assessment of children with such infections, this lack of information may hinder optimal management. We report the results of a one year prospective, hospital based study of all children with fever admitted to our paediatric ward who had recently spent time in the tropics.

\section{Methods, subjects, and results}

From August 1996 to July 1997 all children aged 16 years and under who were admitted with a fever (oral temperature $>37.5^{\circ} \mathrm{C}$ ) and had been in a tropical country within the previous four weeks were entered into the study; details of the few children who had a fever and had been in the tropics but were managed as outpatients were not recorded. Demographic, clinical, and laboratory features were recorded on a standard proforma.

In all, 31 children (18 boys) met the entry criteria; the median age was 4 years (range 5 months to 15 years). The regions visited were south Asia (19), sub-Saharan Africa (11), and the Caribbean (1). Twenty one children were normally resident in the United Kingdom, five in Africa, and five in south Asia; 23 were of south Asian ethnic origin, and eight were Afro-Caribbean. Of the 20 children normally resident in the United Kingdom who had visited a malarious region, only three had been fully compliant with an accepted regimen of antimalarial prophylaxis ${ }^{1}$; eight had taken no prophylaxis, and the other nine were poorly compliant, especially with proguanil.
The table shows the primary diagnoses at discharge from hospital. Fourteen children had non-specific, self limiting illnesses of presumed viral origin. Of the remaining 17 children, seven had potentially fatal infections requiring rapid diagnosis and antimicrobial treatment. All three cases of falciparum malaria were acquired in sub-Saharan Africa, and the single case of vivax malaria originated from India. Ten children had notifiable infectious diseases, and there were no deaths.

Primary diagnoses at discharge in 31 children admitted to hospital with fever after arriving in United Kingdom from the tropics

\begin{tabular}{lccc} 
& \multicolumn{3}{c}{ No of cases } \\
\cline { 2 - 4 } Diagnosis & Resident in UK & $\begin{array}{c}\text { Not resident } \\
\text { in UK }\end{array}$ & Total \\
\hline Non-specific fever & 10 & 4 & 14 \\
\hline Malaria*: & 2 & 1 & 3 \\
\hline Falciparum malaria & 0 & 1 & 1 \\
\hline Vivax malaria & 3 & 0 & 3 \\
\hline Bacillary dysentery ${ }^{*} \dagger$ & 2 & 0 & 2 \\
\hline Dengue fever & 2 & 0 & 2 \\
\hline Typhoid ${ }^{*}$ & 0 & 1 & 1 \\
\hline Acute hepatitis A & 1 & 0 & 1 \\
\hline Bacterial lymphadenitis & 0 & 1 & 1 \\
\hline Pneumonia & 0 & 1 & 1 \\
\hline Pneumocystis carinii pneumoniał & 0 & 1 & 1 \\
\hline Acute myeloid leukaemia & 1 & 0 & 1 \\
\hline Streptococcal throat infection & & &
\end{tabular}

*Notifiable infections.

†Positive stool isolates: shigella (1 case), salmonella (1).

‡Newly diagnosed HIV infection.
Children's Services Directorate, Northwick Park and St Mark's NHS Trust, Harrow, Middlesex HA1 3U John L Klein, senior house officer Guy C Millman, senior house officer Correspondence to: Dr J L Klein, 177 Purves Road, Kensal Rise, London NW10 5TH Johnlklein@email. msn.com

BMJ 1998;316:1425-6 


\section{Comment}

Although a large prospective study of fever in returning travellers has recently been published by researchers at the Hospital for Tropical Diseases in London, ${ }^{2}$ the patients in that study were highly selected and did not include children. To our knowledge this is the first prospective study of fever in children in the United Kingdom who have recently spent time in the tropics. Although the proportion of minor, self limiting illnesses would probably have been higher in children seen in general practice, we have documented a relatively high incidence of potentially fatal tropical infections in those referred to hospital. As the clinical features of malaria are frequently non-specific, and the diagnosis cannot be excluded by a single negative blood test, children at risk of this disease usually require hospital admission, with subsequent investigation by professionals with a detailed knowledge of the local prevalence of specific diseases. ${ }^{3}$

As in retrospective reviews of imported malaria, ${ }^{1}$ most of the cases in our study were among children of former immigrants who had visited their family's country of origin, with south Asia being the commonest destination (reflecting the large local south Asian community). The complete absence of white children in this study is remarkable, perhaps reflecting a reluctance in this section of the community to take children to exotic holiday locations. The poor understanding of the risks associated with travel in our study population is well illustrated by their underuse of antimalarial prophylaxis. Proguanil, which is available only as tablets, was particularly poorly tolerated, highlighting the need for a liquid suspension that is more palatable to children. With more than two children a month being admitted to our unit with potentially life threatening tropical infections, paediatricians in the United Kingdom clearly need a good working knowledge of these conditions, especially as access to specialists in tropical medicine is limited.

We thank Dr H B Valman and Professor G Pasvol for their helpful comments.

Contributors: JLK had the original idea for the study, designed the proforma for data collection, and is the guarantor for the paper. Both JLK and GCM collected the data and wrote the paper.

Funding: None.

Conflict of interest: None

1 Brabin BJ, Ganley Y. Imported malaria in children in the UK. Arch Dis Child 1997;77:76-81.

2 Doherty JF, Grant AD, Bryceson ADM. Fever as the presenting complaint of travellers returning from the tropics. QJ Med 1995;88:277-81.

3 Shingadia D, Al-Ansari H, Novelli V. Investigation and diagnosis of fever in the returning traveller. Curr Paediatr 1996;6:108-13.

(Accepted 27 January 1998)
Child Health Monitoring Unit, Department of Epidemiology and Public Health, Institute of Child Health, University College London Medical School, London WC1N 1EH

Carolyn

DiGuiseppi, senior research fellow Ian Roberts, director

Leah Li, medical statistician Diane Allen, data manager

Correspondence to: Dr DiGuiseppi

C.DiGuiseppi@ich. ucl.ac.uk

BMJ 1998;316:1426-8
The annual distance walked by children has fallen $28 \%$ since 1972, partly because car travel has replaced walking on many school journeys. ${ }^{1}$ Increasing car use has been linked with obesity, adverse health effects in later life, limitations on children's independence, traffic congestion, and pollution. ${ }^{23}$ To inform the development of strategies to reduce school related car travel, we surveyed the travel patterns of urban primary school children.

\section{Methods and results}

The survey was conducted in the inner London boroughs of Camden and Islington. The questionnaire-based partly on published surveys ${ }^{45}$ and prepared in English, Bengali, Turkish, Greek, and Cantonese (first languages of $85 \%$ of eligible pupils)asked about that day's school journey, children's independent travel, and parental concerns. From the sampling frame of all primary schools (excluding pilot, boarding, and special schools), 31 of the 100 eligible schools were randomly selected. We weighted sampling probability by combined class sizes in year 2 (ages 6-7 years) and year 5 (ages 9-10). Questionnaires, with a letter from the head teacher and a multilingual request form for translation, were distributed to pupils for completion at home. Questionnaires were left for absentees. One week later, we collected completed questionnaires, gave new questionnaires to nonrespondents, and distributed requested translations. All pupils were given pencil cases.

We used logistic regression, including a random effect (school) to account for cluster sampling, to estimate odds ratios and 95\% confidence intervals for determinants of car travel versus walking. We excluded pupils who used public transport.

Thirty schools (97\%) agreed to participate. Of 2476 enrolled children, $2086 \quad(84 \%)$ returned usable questionnaires: 96\% English, 2\% Bengali, 1\% Turkish, and 1\% English and Bengali (duplicate versions returned). Response rates were highest in independent schools $(96 \%)$ and lowest in local authority schools (81\%). Excluding independent schools, for which the information was unavailable, the respondents' ethnic distribution (54\% white, 18\% black, 14\% Asian, and $15 \%$ other) was similar to that of the school population ( $50 \%$ white, $18 \%$ black, $15 \%$ Asian, $17 \%$ other).

Most children walked $(69 \%)$ or travelled by car $(26 \%)$. Four $(0.2 \%)$ cycled, and the rest travelled by bus, underground, or train (5\%). Proportions were similar for the journey home. Adults accompanied $84 \%$ of children to and from school. Most children (61\%) were rarely or never allowed out without an adult for school or leisure. Only $3 \%$ of bicycle owners were allowed to cycle on main roads. Ninety per cent of parents were 